\title{
Megacity indicator system for disaster risk management (MegaIST): integrated assessment of physical risks in Istanbul
}

\author{
E. Y. Menteşe ${ }^{1}$, B. Ergün Konukcu ${ }^{1}$, O. Kılıç ${ }^{1}$ \& B. Khazai ${ }^{2}$ \\ ${ }^{1}$ Directorate of Earthquake and Ground Research, \\ Istanbul Metropolitan Municipality, Turkey \\ ${ }^{2}$ Center for Disaster Risk Management, \\ Karlsruhe Institute of Technology, Germany
}

\begin{abstract}
Decision makers need tools to understand the priorities and to set up benchmarks and track progress in their disaster management systems, so that they can justify decisions and investments. MegaIST achieves these goals by analyzing the earthquake risk in three sub-categories. Urban seismic risk, coping capacity and disaster risk management index are the main components of the system. In this study, the results for the physical risk will be presented. The physical risk is calculated for all 954 sub-districts of Istanbul with a comprehensive approach including sub-indicators such as casualties, building damages, infrastructure damages, road blockages and fire ignition probabilities. These indicators are assessed through an Analytical Hierarchy Process and compared to each other resulting Physical Risk Index based on the risk values of the sub-districts.

Keywords: disaster risk reduction, earthquake, Istanbul, indicators.
\end{abstract}

\section{Introduction}

With the development of a comprehensive Earthquake Master Plan for Istanbul and the implementation of a suite of disaster risk reduction initiatives in Istanbul, such as microzonation studies, urban renovation and rejuvenation programs in pilot areas and the seismic strengthening of infrastructure and critical buildings, the Istanbul Metropolitan Municipality is at a point where 
decisions are becoming difficult to make, as the priorities are sometimes not clear or there may be too many competing interests.

In order to overcome this obstacle, IMM has developed Megacity Indicator System for Disaster Risk Management (MegaIST) (in collaboration with Kandilli Observatory and Earthquake Research Institute (KOERI), Karlsruhe Institute of Technology (KIT), Earthquake and Megacities Initiative (EMI) to determine thresholds for assessing the level of achievement in disaster management activities that leads to adjustment of the disaster risk reduction strategies.

The models and methodology referred to here as the "Megacity Indicators System" approach was originally developed for the Inter-American Development Bank through the IDB-IDEA Indicators Program (Cardona et al. [1]), by the Institute of Environmental Studies (IDEA) of the National University of Colombia, Manizales (NUCM). Together with its partners at Manizales, the International Center of Numerical Methods in Engineering (CIMNE) of the Technical University of Catalonia, and local counterparts in the Philippines, EMI undertook a preliminary application of the approach to megacities in Metro Manila (EMI [2]). In the context of EMI's Cross-Cutting Capacity Development (3cd) Program methodology and approach, Megacity Indicators System is used as an innovative risk communication tool to engage stakeholders in understanding their involvement and taking ownership of the risk factors in the city. Besides the implementation in Metro Manila, many other related applications of the model have been undertaken by the IDEA-CIMNE team, and the methodology has been tested and evaluated in other cities and sub-national regions in Latin America and Europe, including Manizales (Colombia) Quito (Ecuador), Barcelona (Spain) and Lombardy region (Italy).

Basically the method is based on an integrated disaster risk assessment approach. There have been different types of risk assessment approaches developed; Kiremidjian et al. [3], Hewitt [4], Davidson and Shah [5], FEMA [6], Karaman et al. [7], Duzgun et al. [8] and many others, where all try to quantify the level of disaster risk and vulnerability in particular.

In this study, integration of 3 main parameters; Urban Seismic Risk Index (USRi), Coping Capacity Index (CCi) and Disaster Risk Management Index (DRMi) are analyzed and assessed together to evaluate the total earthquake risk in Istanbul metropolitan area at a district level. The reason for taking "seismic" risk into account is because the project area "Istanbul" is suited mainly on an earthquake prone location. The utmost output of the study has been the relative ranking of the districts based on their level of total earthquake risk depending on three parameters mentioned above. But so far only physical risk assessment has been established $100 \%$ while others are still being worked on. Therefore this paper should be approached as a theoretical background paper and a progress report.

\section{Method}

The Megacity Indicators System for Istanbul (MegaIST) is composed of three separate but complimentary indicator sets: 
- Urban Seismic Risk Index (USRi)

- Coping Capacity Index (CCi)

- Disaster Risk Management Index (DRMi)

The approach used here for developing the system is developed from a holistic point of view; that is, an integrated and comprehensive approach to guide decision-making. Evaluation of the potential physical damage (hard approach) as the result of the convolution of hazard and physical vulnerability of buildings and infrastructure is the first step of this method. Subsequently, a set of fragility conditions in society that potentially aggravate the physical effects are also considered (soft approach). Together these two steps produce a landscape of total risk for the entire metropolis as the Urban Seismic Risk Index (USRi) and allow decision makers to evaluate or rank sub regions (e.g. administrative districts) according to the total risk.

According to the MegaIST approach, after representing total risk for the entire metropolitan area, the ability of a particular target audience to cope, respond and manage the effects of a disaster has to be captured through a complimentary set of indicators. In defining these indicators it is important that the needs and mandates of a particular set of decision makers is considered, otherwise the indicators would be too general to be meaningful. While the USRi is developed for the whole of Istanbul and can be used by any interested stakeholder, the Coping Capacity Index (CCi) is developed by considering the particular needs of a specific target audience - in this case the Istanbul Metropolitan Municipality. The USRi and CCi are both quantitative indicators which are based on detailed assessments of the earthquake hazard and risk in Istanbul, the vulnerability of society and its capacity to respond.

A final step in the MegaIST approach is to capture the potential for disaster risk management through a set of descriptive performance indicators and track progress (or lack of progress) on pre-defined benchmarks of corrective and prospective intervention. This concludes into the development of the Disaster Risk Management Index (DRMi), which like the $\mathrm{CCi}$ is developed to address the mandates of a target group of decision makers, however, rather than providing quantitative indicators of risk and capacity, the DRMi produce qualitative performance indicators. The DRMi are scores which are derived from a selfassessment along key functional activities policies for DRM by key stakeholders at the Istanbul Metropolitan Municipality. Figure 1 shows how the three indicator sets of the system, complement each other, but at the same time each indicator set is also a whole onto its own.

It should be noted that in the current implementation of the MegaIST, direct and indirect economic losses are not being considered. Obviously, the economic vulnerability in a city such as Istanbul is of great importance and should be accounted for in any framework which intends to describe urban risk from a holistic perspective. However, this requires additional effort and expertise, which is currently beyond the scope of this study. In the future, a set of indicators which reflect not only the potential for direct damage to economic assets, but also indirect or flow losses influenced by dependences in the economic 
production, the robustness of the supply chain and infrastructure as well as potential domino-effects, must be developed and integrated into this framework.

\subsection{Urban Seismic Risk Index (USRi)}

The theoretical and analytical methodological framework for the Urban Seismic Risk Index (USRi) is based on the work of Cardona et al. [1] and Cardona and Birkmann [9], provide an overview of not only the expected direct damages, but also the potential for aggravating impact of the direct damages by the social fragility and lack of resilience of the different districts in Istanbul. According to this procedure, a physical risk index is obtained, for each unit of analysis, from existing loss scenarios, whereas the total risk index is obtained by factoring the risk index by an impact factor, based on variables associated with the socioeconomic conditions of each unit of analysis. In the Istanbul implementation, the USRi combines the direct impact of expected physical damage, "physical" risk factors, and indirect "impact" factors that account for the socio-economic vulnerability within the city's population.

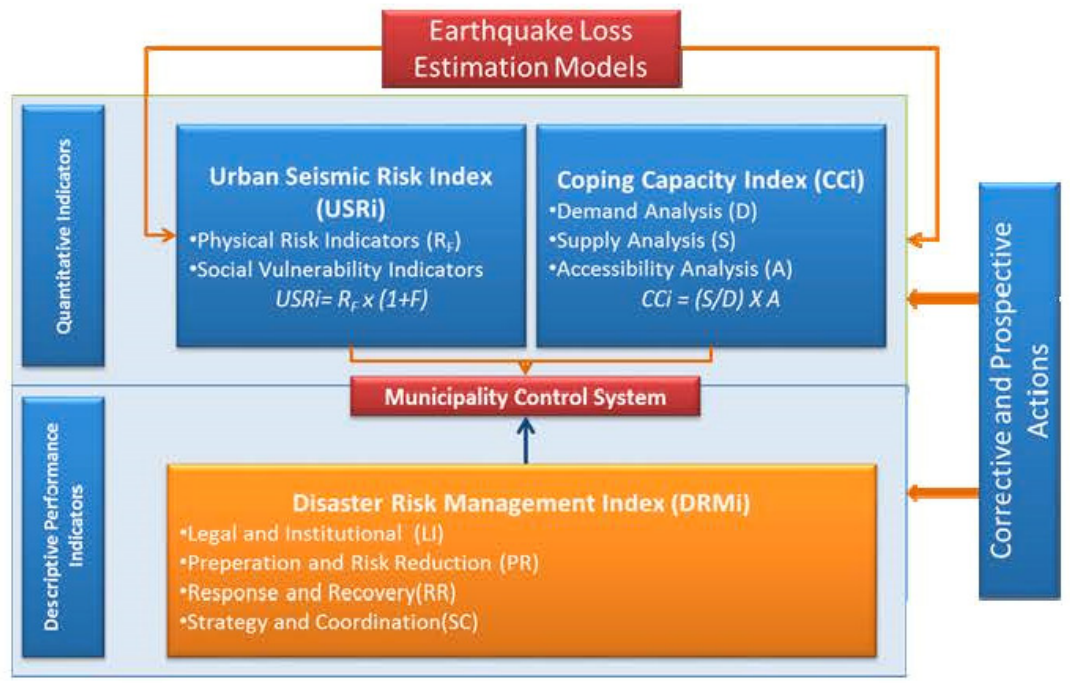

Figure 1: Conceptual model for MegaIST showing how USRi, CCi and DRMi models combine together.

The potential direct impact of an earthquake, for example, is denoted as Physical Risk, $R_{F}$. The indirect effects are given by and impact factor $(1+F)$, which is based on an aggravating coefficient, F. Thus the total Urban Seismic Risk Index (USRi) at the level of the municipality $(\mathrm{m})$ is given by the following expression:

$$
U S R i_{m}=\sum_{i=1}^{m} R_{F_{i}} \times\left(1+F_{i}\right)
$$


The physical risk, $R_{F}$ and the aggravating coefficient, $F$, for each district (i) are in turn the weighted sum of each physical risk indicators $\left(R_{F_{j}}\right)$ and social fragility indicators $\left(F_{f_{k}}\right)$ and social resilience indicators $\left(F_{r_{l}}\right)$ in each district (i) and given by:

$$
R_{F_{i}}=\sum_{j=1}^{n} R_{F_{j}} \times w_{j} \quad \text { and } \quad F_{i}=\sum_{k=1}^{n} F_{f_{k}} \times w_{f_{k}}+\sum_{l=1}^{n} F_{r_{l}} \times w_{r_{l}}
$$

\subsubsection{Suggested indicators for physical risk (RF)}

There are several aspects of the impacts induced by earthquakes and among others, physical results are the most obvious ones since they can be assessed, perceived and monitored more easily than social or economical ones (Carreño et al. [10]). Based on the literature reviews and expert insights, four major set of physical results are selected. These are casualties, building damage, infrastructure damage and fire outbreak possibility. These main themes are then subdivided into indicators that are used for physical risk analysis.

These indicators are as follows:

- Loss of lives;

- Heavy injuries;

- Building collapse;

- Building heavy damage;

- Drinking water pipeline damage;

- Sewage water pipeline damage;

- Natural gas pipeline damage;

- Road block;

- Fire outbreak.

The raw input data for physical indicators are gathered from the "Earthquake Loss Estimation Routine-ELER" software that is developed by Kandilli Observatory and Earthquake Risk Institute (KOERI) under the JRA-3 component of the EU FP-6 NERIES Project. The software is mainly developed for the rapid estimation of earthquake shaking and losses in the Euro-Mediterranean region (KOERI [11]).

The data gathered from ELER are all in same units corresponding to a quantity (e.g. number of collapsed buildings, number of injured persons, number of fire outbreak) except "road block" that is the percentage of the blocking of the roads in reference grid. The software uses a grid based system to estimate the damage which constitutes of $555 \mathrm{~m} \times 418 \mathrm{~m}$ grids.

In order to use the data in managerial level, the data had to be transformed into jurisdictional base and since the smallest unit is sub-district in Istanbul; the grids are converted to sub-district level in GIS environment (fig. 2).

\subsection{Suggested indicators for social vulnerability $\left(S_{v}\right)$}

As stated above, in this study, social vulnerability is accepted as a factor that increases the impact level of physical risk. The main themes for the social vulnerability are demographic state, educational level, health state, mobility, and solidarity and community preparedness level of households. It must be noted 
that, lack or scarcity of these themes are assumed to increase social vulnerability of the community (Cardona and Birkmann [9]). In this study, social vulnerability indicators are determined as follows: demographic structure of households, economic structure, disability and special treatment needs, education status, access to health service, mobility and community preparedness

The input data for social vulnerability can only be gathered via detailed surveys. This has been accomplished in pilot level yet; covering 50 of 934 subdistricts of Istanbul. Based on the official opinion of Turkish Statistical Institute; the survey requires around 35000 household samples in order to represent whole metropolitan area in sub-district level and household based.
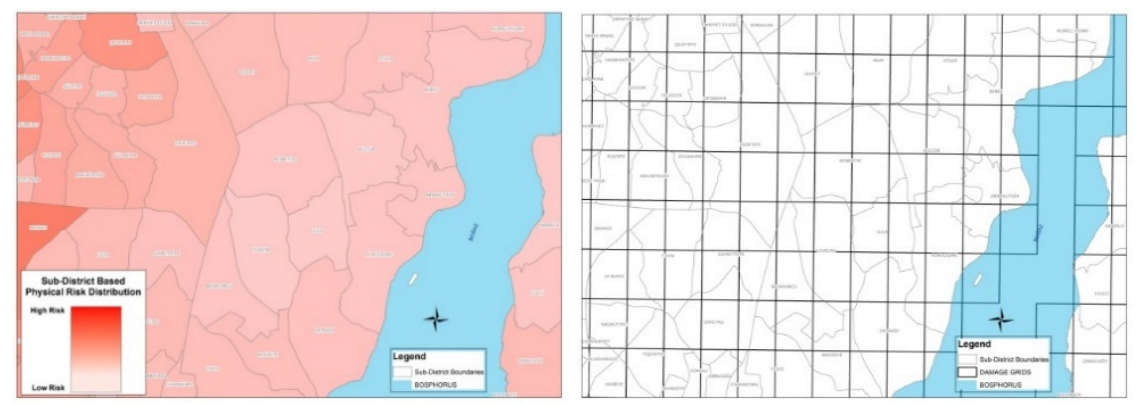

Figure 2: Conversion from grid base format to sub-district based.

\subsection{Coping Capacity index (CCi)}

The municipality's operational capacity to cope with the consequences of an earthquake constitutes the Coping Capacity indicator (CCi), which is quantitatively estimated for each district. The CCi provides stakeholders at IMM with a tool to evaluate in which districts it is lacking operational resources and where the supply in its resources may meet or exceed the demand that is derived from the risk assessment. The $\mathrm{CCi}$ and USRi are complimentary indicator sets and can be used together to see for example which districts have the greatest total risk and also those that lack the most capacity to respond. The CCi and DRMi are also complimentary indicators. Whereas, $\mathrm{CCi}$ quantitatively describe the municipalities' operational capacity to cope and respond to a major earthquake In Istanbul in terms of its resources, the DRMi are performance indicators which qualitatively describe the functional capacity of the municipalities in terms of its disaster risk management policies and strategies. Another important distinction is that DRMi are not district-specific and are estimated for the entire city, whereas $\mathrm{CCi}$ and USRi are computed for each district in Istanbul.

The total coping capacity at the level of the municipality $(\mathrm{m})$ is the weighted sum of four types of coping capacity at IMM $(\mathrm{j}=$ debris removal, rescue and relief, lifeline restoration, and shelter site support) over the number of different districts in Istanbul (j), according to the following expression:

$$
C C i_{m}=\sum_{i=1}^{\mathrm{m}} \sum_{j=1}^{4} C_{i j} \cdot w_{j}
$$


Capacity for each of the indicator types is defined as a simple ratio of the supply of available resources at the municipality to the demand made on these resources as well as accessibility of these resources. In this way the results of a scenario risk assessment which are used to determine the demand on resources are factored directly into the calculation of capacity and allow IMM to leverage the results of the detailed risk study in the context of its own resource allocation and planning needs.

$$
\text { Capacity }=\frac{\text { Supply }}{\text { Demand }} \times \text { Accessibility }
$$

\subsubsection{Suggested indicators for coping capacity (CCi)}

The aim here was to define coping capacity indicators based on the direct mandate and responsibilities of the various departments and directorates at IMM in responding and coping with a disaster in Istanbul. Disaster Management Center of IMM (AKOM) houses the information on where IMM's operational capacity resides and an operational flow model which identifies the roles and responsibilities of IMM's various institutions to respond and cope with the consequences of an earthquake.

According to the AKOM framework, the municipality's operational activities in responding and recovering from an earthquake constitutes the management of immediate response, relief and recovery efforts, including the removal of debris, search and rescue operations and fire extinguishing after an earthquake. It also includes the return to normalcy in the provision of fundamentally important services such as transportation, gas, water and sewage systems as well as supporting the shelter sites with basic services. Thus, the following four indicators are defined as the coping capacity indicators of IMM: Debris Removal, Rescue and Relief Capacity (search and rescue, fire fighting, burial capacity), Lifeline Restoration (natural gas, sewage, drinking water) and Shelter Site Support (food distribution, water distribution, bread distribution) Capacity.

\subsection{Disaster Risk Management Index (DRMi)}

The Disaster Risk Management index is used as a "control system" in the MegaIST framework, for the Municipality to measure performance and effectiveness of different operational and organizational policies and their effect on the total Urban Seismic Risk in the different districts of Istanbul. The Disaster Risk Management Index permits a systematic and quantitative benchmarking of different functional capacities and policies at the Municipality during different periods. The DRMi are "macro" indicators for measuring progress on disaster risk reduction management for the Municipality of Istanbul. They are presented in four broad indicator groups: Legal and Institutional Requirements $\left(D R M I_{L I}\right)$, Risk Reduction Implementation and Preparedness Activities $\left(D R M I_{P R}\right)$, Readiness to Respond and Recover $\left(D R M I_{R R}\right)$ and Strategy and Coordination $\left(D R M I_{S C}\right)$.

$$
D R M I=D R M I_{L I} \times w_{L I}+D R M I_{P R} \times w_{P R}+D R M I_{R R} \times w_{R R}+D R M I_{S C} \times w_{S C}
$$




\section{Implementation approach}

Each of the indicator sets depicted in MegaIST are derived from a set of quantitative or descriptive indicators, which must be assigned importance weights. In the case of the quantitative indicators they first have to be transformed between values of 0 and 1 . Thus the procedure for implementing the MegaIST methodology involves the following four steps; collecting and analyzing data for selected indicators; developing transformation functions to normalize indicators; implementation of indicators and their transformation functions with a set of "borrowed" weights in the Megacity Indicators System and generating the index for the selected project area.

To aid in the implementation process an interactive software tool, Logical Decisions for Windows (LDW) is used to evaluate and qualify indicators and examine their effects upon the total output. The implementation in Manila has been tested and validated with the use the software, which was found to be a flexible and practical analytical platform for duplicating the proposed methodology. The software supports performing sensitivity analyses, which can be used to interactively demonstrate variability of the results to different indicators. It also enables an evaluation of the stability of the methodology to variability of the input data. The advantage of using such a tool that integrates the models is that during a periodic evaluation, other indicators that may have previously not been available or simply overlooked can be integrated into the framework to obtain a new evaluation of risk and Disaster Risk Management (DRM) practices in Istanbul.

\section{Integrated physical risk analysis}

Hazard study that is based on this analysis results a scenario earthquake on main Marmara Fault (fig. 3) with $\mathrm{Mw}=7.25$ and $\varepsilon=1.4$ with probability of exceedance $10 \%$ in 50 years ( 475 year return period).

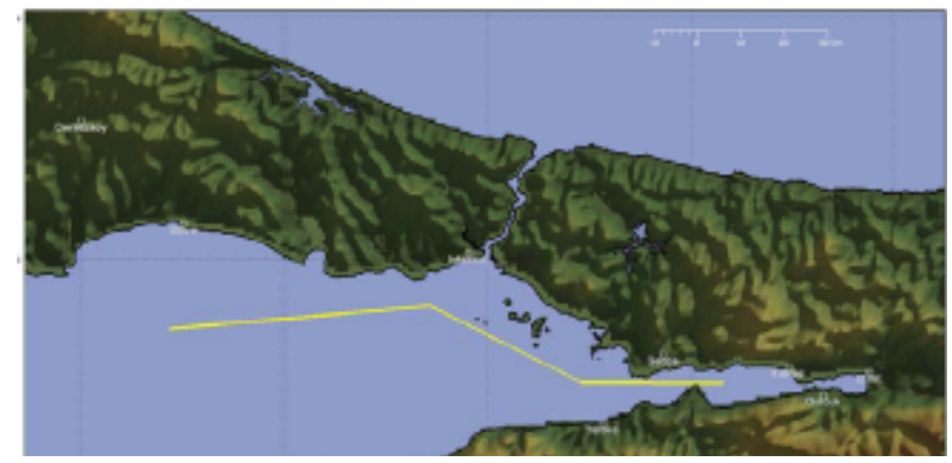

Figure 3: Approximate fault segment in Marmara Sea. 
As mentioned in the methodology in detail, the dataset of ELER is grid based (KOERI [11]), and it does not represent full efficiency in means of its use in decision making procedures. Thus the data had to be converted to sub-district base.

According to ELER results, the most probable earthquake scenario in Istanbul will result approximately 5,000 completely damaged buildings, 20,000 extensively damaged buildings, 16,000 deaths and 16,000 serious injuries, 456 damages on water pipeline network damage, 1478 damages on sewage water pipeline network and 644 damages on natural gas pipelines (KOERI [12]). In addition 423 flammable buildings are estimated to be damaged which are assumed as the main sources of fire outbreaks following an earthquake.

After the grid based ELER results (number of completely and extensively damaged buildings, number of deaths and seriously injured people, percentage of road blockage, number of damages on drinking water, waste water and natural gas pipeline network and damage to flammable buildings and wooden buildings for analyzing fire outbreak possibility) were converted to sub-district base, they were embedded in LDW software database.

So that, each sub-district is represented with their damage values in database. Then these values are (normalized) transformed into common units varying between 0 and 1 where 1 is the highest risk and 0 is the lowest. A screenshot from LDW software can be seen in figure 4 where the depiction of relation between casualty and risk is represented.

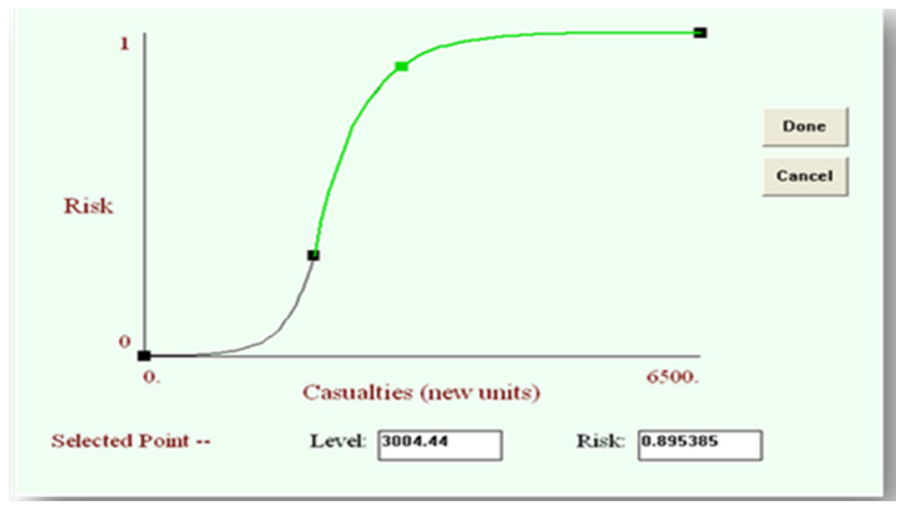

Figure 4: Normalization process.

Thereafter they are weighted based on expert and stakeholder opinions using Analytical Hierarchy Process in LDW software (fig. 5). It must be noted that weightings were done with the perception that priority must be given to the indicator that is the most important and precautions must be taken in this regard. It is seen that the main opinion of the experts is that building damage and its inevitable output loss of lives or injuries must be handled with much more rapidly than any other indicator. These indicators consist of almost $75 \%$ of the whole importance weights. 


\section{WEIGHTS}

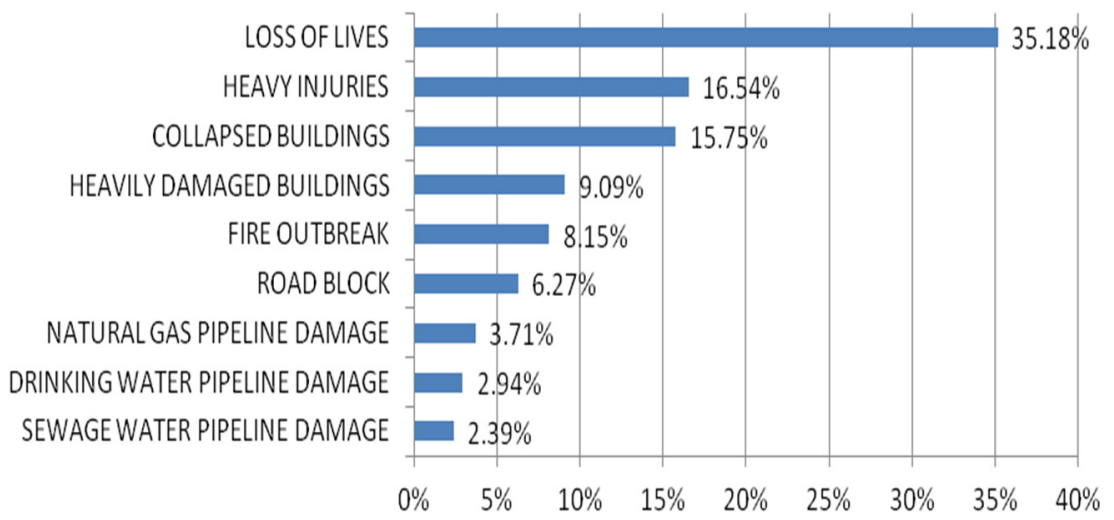

Figure 5: Percentage weights of the physical indicators.

After the weightings are done, each sub-district gets a risk value varying between 0 and 1 . This data basically depends on the damages but they are normalized to be indexed and weighted based on their importance. As a result total physical risk map of Istanbul is generated as seen in figure 6.

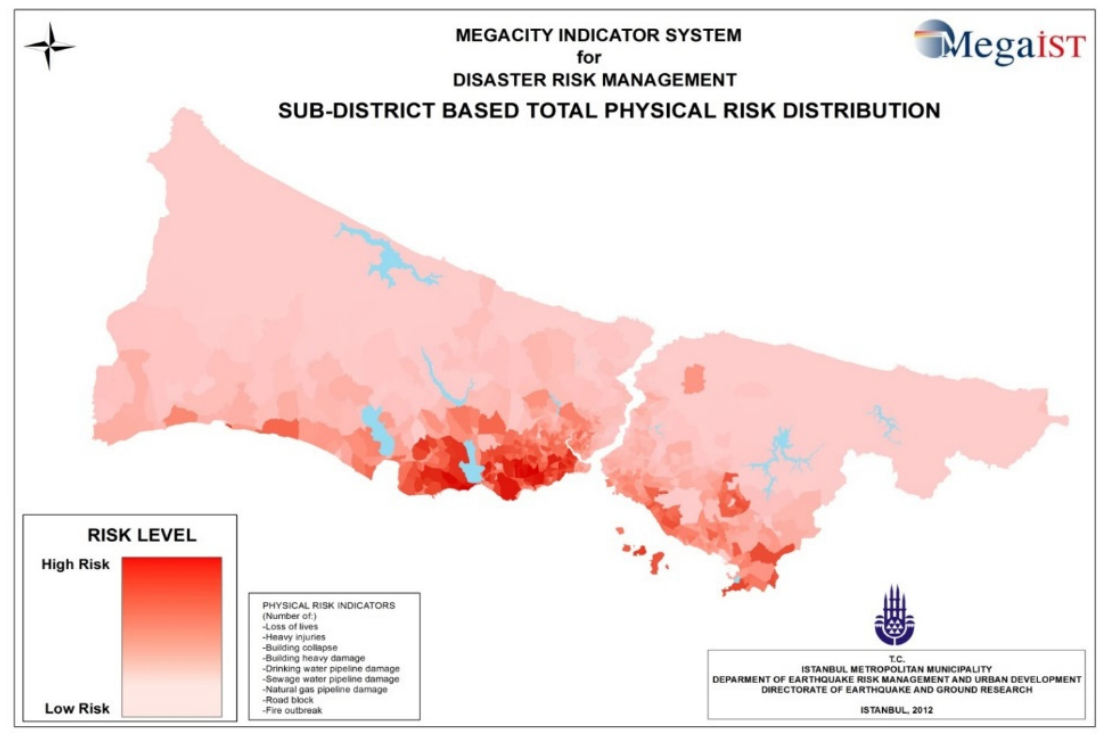

Figure 6: Sub-district based physical risk level distribution in Istanbul. 


\section{Results and discussion}

According to the results, it is observed that, especially the southern part of the European side of Istanbul is prone to risk more than other parts of the whole metropolitan area. It is because this area has the maximum numbers of casualty and building damages that also have the highest weights.

The map also shows that urban structure of Istanbul lacks earthquake safety, since rural areas are mostly performing well in means of resiliency; but urbanized areas have higher risk values. This is definitely a result of uncontrolled and unauthorized urbanization process in the last 50 years. The results also show correlation with the JICA study [13] although having different numbers, the damage pattern shows criticality in the same region.

The significance and uniqueness of this analysis is that, it is not solely a damage estimation approach; it is a model that combines various types of risks and generates an integrated and holistic output that enlightens the decision makers on where they should start to reduce risks. To be able to prioritize the DRR actions is crucial in a risk prone city such as Istanbul that can save thousands of lives. Another important part of the study is that it can give input on how the stakeholders and experts reach to possible risks; how they weight the importance of these indicators.

This analysis has been conducted as a part of MegaIST project which is explained in detail in first sections. In forthcoming two years it is aimed at developing and completing the other parts of the project and finalizing the overall index constituting of not only physical, but also social, institutional and organizational aspects of disasters.

\section{Acknowledgements}

The authors of this paper would like to thank Mr. Fouad Bendimerad (President of Earthquake and Megacities Initiative) who motivated and inspired us in the first place. In addition we would like to thank Prof. Mustafa Erdik, Head of Kandilli Observatory and Earthquake Research Institute (KOERI) for his technical assistance and invaluable consultancy, Mrs. Bilgen Sungay again from KOERI for her active participation in our discussions and Istanbul Metropolitan Municipality for providing us technical and administrative conditions to carry out this study.

\section{References}

[1] Cardona, O.D., Hurtado, J. E., Duque, G., Moreno, A., Chardon, A.C. \& Velásquez, L.S., System of Indicators for Disaster Risk Management, Main Technical Report, Manizales, 2005.

[2] Earthquake and Megacities Initiative, Application of Indicators in Urban and Megacities Disaster Management, A Case Study for Metro Manila. Progress Report, Manila, 2006. 
[3] Kiremidjian, A., Moore, J., Fan, Y. Y., Yazlalı, O., Basoz, M. \& Williams, M., Seismic risk assessment of transportation network systems. Journal of Earthquake Engineering, 11, pp. 371-382, 2007.

[4] Hewitt, K., Regions of Risk: A Geographical Introduction to Disasters. Longman, Essex, 1997.

[5] Davidson, R. \& Shah, H.C., A multidisciplinary urban earthquake disaster risk index. Earthquake Spectra, 13(2), pp. 211-223, 1997.

[6] Federal Earthquake Management Association (FEMA), HAZUS: user's manual and technical manuals. vol 1-4., Washington, DC, 1999.

[7] Karaman, H., Sahin, M. \& Elnashai, A. S., Earthquake loss assessment features of Maeviz-Istanbul (Hazturk), Journal of Earthquake Engineering, 12, pp. 175-186, 2008.

[8] Duzgun, H. S. B., Yucemen, M. S., Kalaycioglu, H. S., Celik, K., Kemec, S., Ertugay. K. \& Deniz A., An integrated earthquake vulnerability assessment framework for urban areas. Nat Hazards, 59, pp. 917-947, 2011.

[9] Cardona, O.D. \& Birkmann, J., (eds). A System of Indicators for Disaster Risk Management in the Americas, Measuring Vulnerability to Hazards of Natural Origin: Towards Disaster Resilient Societies, United Nations University Press, Tokyo, 2006.

[10] Carreño, M.L, Cardona, O.D. \& Barbat, A.H., A disaster risk management performance index, Journal of Natural Hazards, 41(1), pp. 1-20, 2007.

[11] Kandilli Observatory and Earthquake Research Institute (KOERI), Earthquake Loss Estimation Routine (ELER) Damage Loss Estimation Software, User Manual. http://www.koeri.boun.edu.tr/depremmuh/eski/ ELER/ELER_v3_Manual.pdf

[12] Kandilli Observatory and Earthquake Research Institute (KOERI), Updating Estimations of the Probable Earthquake Loss Estimations in Istanbul, Project Report, Istanbul, 2009.

[13] Japan International Cooperation Agency, Disaster Prevention and Mitigation Basic Plan in Istanbul including Seismic Microzonation, Final Report, Istanbul, 2002. 